Article

\title{
Cytotoxic Secondary Metabolites Isolated from the Marine Alga-Associated Fungus Penicillium chrysogenum LD-201810
}

\author{
Lin-Lin Jiang ${ }^{1,2,3,+}{ }^{\dagger}$ Jin-Xiu Tang ${ }^{1,+}$, Yong-Heng Bo ${ }^{2}$, You-Zhi Li ${ }^{2}$, Tao Feng ${ }^{2}$, \\ Hong-Wei Zhu ${ }^{1,2,3}$, Xin Yu ${ }^{1,2,3}$, Xing-Xiao Zhang ${ }^{1,3, *}$, Jian-Long Zhang ${ }^{1,2,3, *}$ and Weiyi Wang ${ }^{4, *}$ \\ 1 School of Life Sciences, Ludong University, Yantai 264025, China; linlinjiang1986@163.com (L.-L.J.); \\ TJX19950209@163.com (J.-X.T.); hngwzhu@outlook.com (H.-W.Z.); yuxinzghn@163.com (X.Y.) \\ 2 Shandong Provincial Key Laboratory of Quality Safty Monitoring and Risk Assessment for Animal Products, \\ Ji'nan 250022, China; yongheng1980@163.com (Y.-H.B.); liyouzhi2009@126.com (Y.-Z.L.); \\ fengtaojn2019@163.com (T.F.) \\ 3 Yantai Key Laboratory of Animal Pathogenetic Microbiology and Immunology, Yantai 264025, China \\ 4 Key Laboratory of Marine Biogenetic Resources, Third Institute of Oceanography, Ministry of Natural \\ Resources, Xiamen 361005, China \\ * Correspondence: zhangxingxiao@ldu.edu.cn (X.-X.Z.); zhangjianlong@ldu.edu.cn (J.-L.Z.); \\ wywang@tio.org.cn (W.W.); Tel.: +86-535-6673485 (X.-X.Z.); +86-535-6681162 (J.-L.Z.); \\ +86-592-219-5518 (W.W.) \\ + These authors contributed equally to this work.
}

Received: 6 May 2020; Accepted: 20 May 2020; Published: 22 May 2020

\begin{abstract}
A new pentaketide derivative, penilactonol A (1), and two new hydroxyphenylacetic acid derivatives, $\left(2^{\prime} R\right)$-stachyline B (2) and $\left(2^{\prime} R\right)$-westerdijkin A (3), together with five known metabolites, bisabolane-type sesquiterpenoids 4-6 and meroterpenoids 7 and 8 , were isolated from the solid culture of a marine alga-associated fungus Penicillium chrysogenum LD-201810. Their structures were elucidated based on extensive spectroscopic analyses, including 1D/2D NMR and high resolution electrospray ionization mass spectra (HRESIMS). The absolute configurations of the stereogenic carbons in $\mathbf{1}$ were determined by the $\left(\mathrm{Mo}_{2}(\mathrm{OAc})_{4}\right)$-induced circular dichroism $(\mathrm{CD})$ and comparison of the calculated and experimental electronic circular dichroism (ECD) spectra, while the absolute configuration of the stereogenic carbon in $\mathbf{2}$ was established using single-crystal X-ray diffraction analysis. Compounds $\mathbf{2}$ and $\mathbf{3}$ adapt the $2^{\prime} R$-configuration as compared to known hydroxyphenylacetic acid-derived and $\mathrm{O}$-prenylated natural products. The cytotoxicity of 1-8 against human carcinoma cell lines (A549, BT-549, HeLa, HepG2, MCF-7, and THP-1) was evaluated. Compound 3 exhibited cytotoxicity to the HepG2 cell line with an $\mathrm{IC}_{50}$ value of $22.0 \mu \mathrm{M}$. Furthermore, 5 showed considerable activities against A549 and THP-1 cell lines with $\mathrm{IC}_{50}$ values of 21.2 and $18.2 \mu \mathrm{M}$, respectively.
\end{abstract}

Keywords: alga; marine-derived fungus; Penicillium chrysogenum; polyketide; hydroxyphenylacetic acid; cytotoxicity

\section{Introduction}

Microorganisms belonging to marine ecosystems are diverse both taxonomically and biologically [1-3]. These microorganisms developed unique metabolic pathways to overcome the extreme temperature, nutrient scarcity, high salinity, and ultraviolet radiation [4,5]. As one of the most prevalent biocenoses in marine ecosystems, marine-derived filamentous fungi represent an extraordinarily diverse biotic population. They distribute in almost all marine habitats, including marine plants, marine invertebrates and vertebrates, and marine sediments [2,6-8]. Among them, 
marine alga-associated fungi have drawn considerable attention because they can synthesize valuable secondary metabolites with potential pharmacological properties [6,7].

As part of our ongoing search for bioactive secondary metabolites from marine-derived fungi, the fungus Penicillium chrysogenum LD-201810 was isolated from the marine red alga Grateloupia turuturu. Subsequent chemical investigation of an EtOAc extract of the culture of this fungal strain led to the isolation of a new pentaketide derivative, penilactonol A (1), and two previously unreported hydroxyphenylacetic acid derivatives, $\left(2^{\prime} R\right)$-stachyline B (2) and $\left(2^{\prime} R\right)$-westerdijkin A (3), together with five known metabolites, bisabolane-type sesquiterpenoids 4-6 and meroterpenoids 7 and 8 (Figure 1). The structures and absolute configurations of the stereogenic carbons were unequivocally determined using extensive spectroscopic analyses, $\left(\mathrm{Mo}_{2}(\mathrm{OAc})_{4}\right)$-induced circular dichroism (ICD), time-dependent density-functional theory (TDDFT) electronic circular dichroism (ECD) calculations, and single-crystal X-ray diffraction analyses. To the best of our knowledge, 2 and 3 adapt the $2 ' R$-configuration as compared to known hydroxyphenylacetic acid-derived and $O$-prenylated natural products. Details of the isolation, structure elucidation, and biological activities of the isolated compounds are presented herein.<smiles>CC=C1C=C(C(O)C(C)O)C(=O)O1</smiles><smiles>C=C(C)CCC[C@](C)(O)c1ccc(C(=O)O)cc1O</smiles>

5<smiles>[R]OC(=O)Cc1ccc(OC[C@@H](O)C(=C)C)cc1</smiles>

$2 \mathrm{R}=\mathrm{H}$ $3 \mathrm{R}=\mathrm{Me}$<smiles>CC(C)CCC[C@](C)(O)c1ccc(C(=O)O)cc1O</smiles>

6<smiles>CC(=O)OC[C@H](C)CCC[C@](C)(O)c1ccc(C(=O)O)cc1O</smiles>

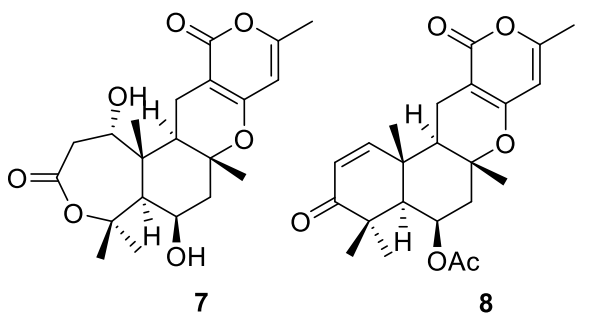

Figure 1. Chemical structures of 1-8.

\section{Results and Discussion}

\subsection{Structure Elucidation}

Compound 1 was obtained as a colorless oil with a molecular formula of $\mathrm{C}_{9} \mathrm{H}_{12} \mathrm{O}_{4}$, established by (+)-HRESIMS $m / z 185.0803[\mathrm{M}+\mathrm{H}]^{+}$, corresponding to four degrees of unsaturation. The ${ }^{1} \mathrm{H}$ NMR spectrum (Table 1) showed two methyl doublets at $\delta_{\mathrm{H}} 1.39\left(\mathrm{~d}, J=6.6 \mathrm{~Hz}, \mathrm{H}_{3}-1\right)$ and $1.88(\mathrm{~d}, J=7.4 \mathrm{~Hz}$, $\left.\mathrm{H}_{3}-8\right)$, one doublet at $\delta_{\mathrm{H}} 4.47(\mathrm{~d}, J=5.4 \mathrm{~Hz}, \mathrm{H}-3)$, and a multiplet at $\delta_{\mathrm{H}} 4.36(\mathrm{~m}, \mathrm{H}-2)$, and one singlet at $\delta_{\mathrm{H}} 7.67(\mathrm{~s}, \mathrm{H}-5)$ and one quartet at $\delta_{\mathrm{H}} 5.60(\mathrm{q}, J=7.4 \mathrm{~Hz}, \mathrm{H}-7)$ attributable to two olefinic protons. The ${ }^{13} \mathrm{C}$ NMR spectrum, along with distortionless enhancement by polarization transfer (DEPT) and HSQC data, demonstrated the presence of two methyls at $\delta_{\mathrm{C}} 19.7$ (C-1) and 11.7 (C-8); four methines, including two oxygenated $\mathrm{sp}^{3}$ at $\delta_{\mathrm{C}} 59.3$ (C-2) and 69.1 (C-3) and two sp ${ }^{2}$ at $\delta_{\mathrm{C}} 140.4$ (C-5) and 112.2 (C-7); and three quaternary carbons, including two $\mathrm{sp}^{2}$ carbons at $\delta_{\mathrm{C}} 132.1$ (C-4) and 148.6 (C-6) and one carbonyl carbon at $\delta_{\mathrm{C}} 168.4(\mathrm{C}-9)$. The COSY correlations (Figure $2 \mathrm{~A}$ ) from $\mathrm{H}_{3}-1$ to $\mathrm{H}-2$ and from $\mathrm{H}-2$ to $\mathrm{H}-3$, combined with the downfield chemical shifts of $C-2\left(\delta_{C} 59.3\right)$ and $C-3\left(\delta_{C} 69.1\right)$, revealed a presence of a vic-diols moiety. The key HMBC correlations from H-2 to C-4, H-3 to C-5, H-5 to C-3 and C-7, $\mathrm{H}_{3}-8$ to C-6, and the COSY correlation of $\mathrm{H}-7$ and $\mathrm{H}_{3}-8$ extended the fragment to $\mathrm{C}-4-\mathrm{C}-8$. The HMBC correlations from H-3 and H-5 to C-9 located the carbonyl carbon C-9 linked to C-4. To satisfy the molecular formula and a degree of unsaturation, C-9 should connect to C-6 by an ester linkage to form the $\alpha, \beta$-unsaturated $\gamma$-lactone ring. Hence, the planar structure of 1 was assigned. The key NOE correlation (Supplementary Materials, Figure S6) between H-5 and H-7 assigned the $\mathrm{Z}$ configuration of the double 
bond between C- 6 and C-7. According to the literature, the coupling constant between the $\mathrm{H}-2$ and $\mathrm{H}-3$ is larger than $4 \mathrm{~Hz}$ in erythro isomers but smaller than $2 \mathrm{~Hz}$ in threo isomers in the $\alpha, \beta$-unsaturated $\gamma$-lactones [9]. Therefore, the coupling constant of $5.4 \mathrm{~Hz}$ between $\mathrm{H}-2$ and $\mathrm{H}-3$ indicated the erythro relative configuration of 2,3-diol in $\mathbf{1}$ [10]. The absolute configuration of the erythro-2,3-diol in $\mathbf{1}$ was determined by the dimolybdenum-induced circular dichroism (ICD) analysis [11]. In the ICD analyses using Snatzke's method with dimolybdenum tetraacetate $\left[\mathrm{Mo}_{2}(\mathrm{OAc})_{4}\right]$ in $\mathrm{MeOH}$, the $\mathrm{Mo}_{2}$-complex of $\mathbf{1}$ gave a negative CD Cotton effect near $400 \mathrm{~nm}$ (Figure 2B). Using Snatzke's helicity rule [11-13], the sign of the $\mathrm{O}-\mathrm{C}-\mathrm{C}-\mathrm{O}$ torsional angle in the favored conformation of the chiral $\mathrm{Mo}_{2}$-complex determines the sign of the CD Cotton effect near $400 \mathrm{~nm}$, and the conformation with an antiperiplanar orientation of the $\mathrm{OH}$ and the methyl group, $\mathrm{O}-\mathrm{C}-\mathrm{C}-\mathrm{CH}_{3}$, is a favored conformation of the $\mathrm{Mo}_{2}$-complex in the erythro-diols closely resembling 1, as shown in Figure 2B. Furthermore, the TDDFT method was employed at the CAM-B3LYP-SCRF/def2-SVP//B3LYP/6-31G(d) level to obtain the calculated ECD spectra of $\mathbf{1}$. The experimental ECD spectrum of $\mathbf{1}$ was in good agreement with that of the calculated for $(2 R, 3 S)-\mathbf{1}$ at this level (Figure 3). Hence, the absolute configurations at C-2 and C-3 in $\mathbf{1}$ were finally determined to be $2 R, 3 S$, respectively.

Table 1. ${ }^{1} \mathrm{H}(500 \mathrm{MHz})$ and ${ }^{13} \mathrm{C}$ NMR $(125 \mathrm{MHz})$ data of compounds 1-3 in DMSO- $d_{6}$.

\begin{tabular}{|c|c|c|c|c|c|c|c|}
\hline \multirow[b]{2}{*}{ No. } & \multicolumn{2}{|c|}{ Compound 1} & \multirow[b]{2}{*}{ No. } & \multicolumn{2}{|c|}{ Compound 2} & \multicolumn{2}{|c|}{ Compound 3} \\
\hline & $\begin{array}{c}\delta_{\mathrm{H}}(\mathrm{Mult}, J \\
\text { in Hz) }\end{array}$ & $\delta_{\mathrm{C}}$, Type & & $\begin{array}{c}\delta_{\mathrm{H}}(\mathrm{Mult}, J \\
\text { in Hz) }\end{array}$ & $\delta_{\mathrm{C}}$, Type & $\begin{array}{c}\delta_{\mathrm{H}}(\mathrm{Mult}, J \\
\text { in Hz) }\end{array}$ & $\delta_{\mathrm{C}}$, Type \\
\hline 1 & $1.39(\mathrm{~d}, 6.6)$ & $19.7, \mathrm{CH}_{3}$ & 1 & & 127.4, C & & $126.3, \mathrm{C}$ \\
\hline 2 & $4.36(\mathrm{~m})$ & $59.3, \mathrm{CH}$ & $2 / 6$ & $7.14(\mathrm{~d}, 8.3)$ & $130.8, \mathrm{CH}$ & $7.15(\mathrm{~d}, 8.6)$ & $130.4, \mathrm{CH}$ \\
\hline 3 & $4.47(\mathrm{~d}, 5.4)$ & $69.1, \mathrm{CH}$ & $3 / 5$ & $6.86(d, 8.3)$ & $114.8, \mathrm{CH}$ & $6.88(d, 8.6)$ & $114.5, \mathrm{CH}$ \\
\hline 4 & & $132.1, \mathrm{C}$ & 4 & & $157.8, \mathrm{C}$ & & 157.6, C \\
\hline 5 & $7.67(\mathrm{~s})$ & $140.4, \mathrm{CH}$ & 7 & 3.46 (br s) & $40.2, \mathrm{CH}_{2}$ & $3.58(d, 5.3)$ & $39.3, \mathrm{CH}_{2}$ \\
\hline 6 & & 148.6, C & 8 & & $173.4, \mathrm{C}$ & & $171.9, \mathrm{C}$ \\
\hline 7 & $5.60(q, 7.4)$ & $112.2, \mathrm{CH}$ & $1^{\prime}$ & $\begin{array}{c}3.92(\mathrm{dd}, 9.9,4.4) \\
3.84(\mathrm{~m})\end{array}$ & 71.3, $\mathrm{CH}_{2}$ & $\begin{array}{l}3.93(\mathrm{dd}, 9.9,4.5) \\
3.86(\mathrm{dd}, 9.9,6.9)\end{array}$ & $70.9, \mathrm{CH}_{2}$ \\
\hline 8 & $1.88(\mathrm{~d}, 7.4)$ & $11.7, \mathrm{CH}_{3}$ & $2^{\prime}$ & $4.24(t, 5.3)$ & $72.7, \mathrm{CH}$ & $4.25(\mathrm{~m})$ & $72.3, \mathrm{CH}$ \\
\hline \multirow[t]{5}{*}{9} & & $168.4, \mathrm{C}$ & $3^{\prime}$ & & $145.8, \mathrm{C}$ & & $145.4, \mathrm{C}$ \\
\hline & & & $4^{\prime}$ & $\begin{array}{l}4.86(\text { br s) } \\
5.02(\text { br s) }\end{array}$ & $112.1, \mathrm{CH}_{2}$ & $\begin{array}{l}4.87 \text { (br s) } \\
5.03(\text { br s) }\end{array}$ & 111.7, $\mathrm{CH}_{2}$ \\
\hline & & & $5^{\prime}$ & $1.72(\mathrm{~s})$ & $18.9, \mathrm{CH}_{3}$ & $1.73(\mathrm{~s})$ & $18.5, \mathrm{CH}_{3}$ \\
\hline & & & 8-OMe & & & $3.58(\mathrm{~s})$ & $51.6, \mathrm{CH}_{3}$ \\
\hline & & & $2^{\prime}-\mathrm{OH}$ & & & 5.23 (br s) & \\
\hline
\end{tabular}

$\mathbf{A}$

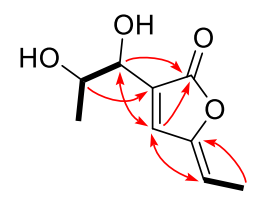

B

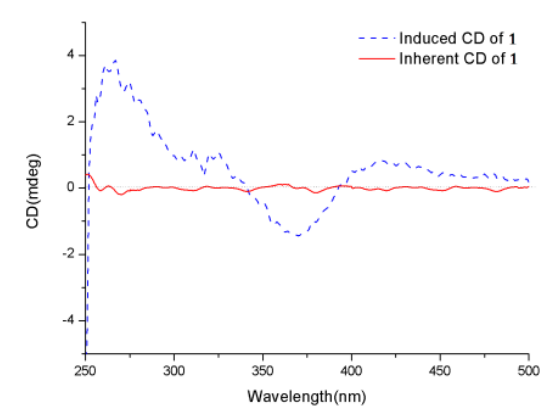<smiles>CC=C(CC)C(O)[C@H](O)CC</smiles>
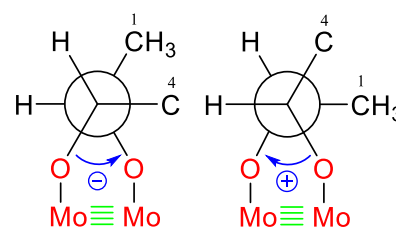

Favored for 1

Figure 2. (A) COSY and key HMBC correlations in 1; (B) induced circular dichroism (ICD) spectra from the $\mathrm{Mo}_{2}$-complex and inherent $\mathrm{CD}$ of $\mathbf{1}$. 


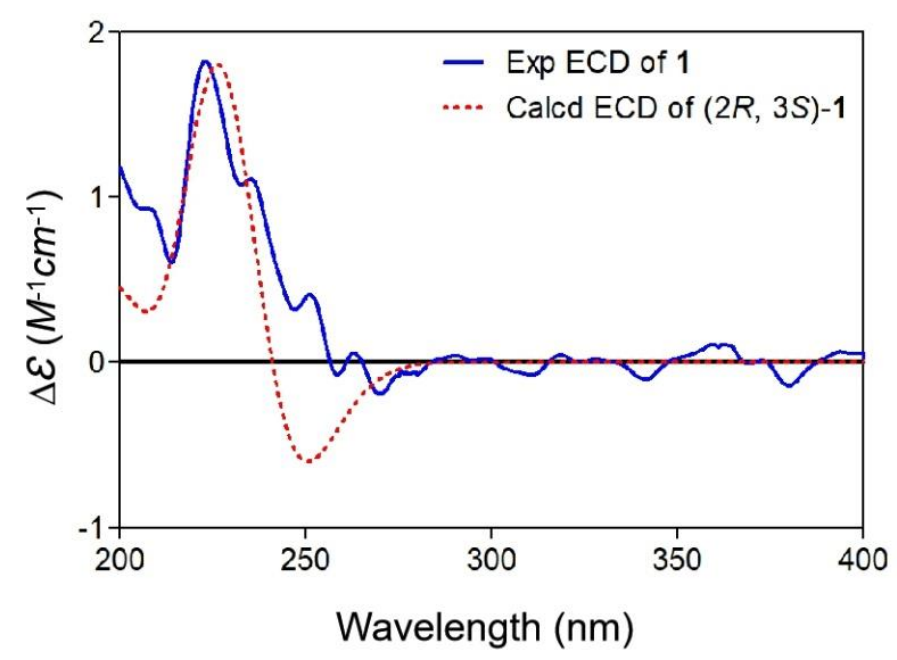

Figure 3. Experimental electronic circular dichroism (ECD) spectrum of $\mathbf{1}$ (blue solid); calculated ECD spectrum of $(2 R, 3 S)-1$ (UV correction $=-19 \mathrm{~nm}$, red dash) at the CAM-B3LYP-SCRF/def2-SVP//B3LYP/6-31G(d) level of theory in $\mathrm{MeOH}$ with IEFPCM solvent model (Polarized Continuum Model using the Intergral Equation Formalism).

Compound 2 was acquired as colorless needles. The molecular formula $\mathrm{C}_{13} \mathrm{H}_{16} \mathrm{O}_{4}$ was established on the basis of (+)-HRESIMS data at $m / z 254.1389\left(\left[\mathrm{M}+\mathrm{NH}_{4}\right]^{+}\right)$and $259.0942\left([\mathrm{M}+\mathrm{Na}]^{+}\right)$. The ${ }^{1} \mathrm{H}$ and ${ }^{13} \mathrm{C}$ NMR data (Table 1), in combination with the HSQC spectrum, displayed signals that were attributed to one methyl at $\delta_{\mathrm{H}} 1.72\left(\mathrm{~s}, \mathrm{H}-5^{\prime}\right)$ and $\delta_{\mathrm{C}} 18.9\left(\mathrm{C}-5^{\prime}\right)$; three methylenes, including one oxygenated sp ${ }^{3}$ at $\delta_{\mathrm{H}} 3.92\left(\mathrm{dd}, J=9.9,4.4 \mathrm{~Hz}, \mathrm{H}-1^{\prime} \alpha\right), 3.84\left(\mathrm{~m}, \mathrm{H}-1^{\prime} \beta\right)$, and $\delta_{\mathrm{C}} 71.3\left(\mathrm{C}-1^{\prime}\right)$, one sp ${ }^{3}$ at $\delta_{\mathrm{H}}$ 3.46 (br s, H-7) and $\delta_{\mathrm{C}} 40.2$ (C-7), and one exocyclic sp ${ }^{2}$ at $\delta_{\mathrm{H}} 4.86$ (br s, H-4' $\alpha$ ), 5.02 (br s, H-4' $\beta$ ) and $\delta_{\mathrm{C}} 112.1\left(\mathrm{C}-4^{\prime}\right)$; five methines, including four $\mathrm{sp}^{2}$ at $\delta_{\mathrm{H}} 7.14(\mathrm{~d}, J=8.3 \mathrm{~Hz}, \mathrm{H}-2 / 6), 6.86(\mathrm{~d}, J=8.4 \mathrm{~Hz}$, $\mathrm{H}-3 / 5), \delta_{\mathrm{C}} 130.8(\mathrm{C}-2 / 6), 114.8(\mathrm{C}-3 / 5)$, and one $\mathrm{sp}^{3}$ at $\delta_{\mathrm{H}} 4.24\left(\mathrm{t}, J=5.3 \mathrm{~Hz}, \mathrm{H}-2^{\prime}\right)$ and $\delta_{\mathrm{C}} 72.7\left(\mathrm{C}-2^{\prime}\right)$; three non-protonated $\mathrm{sp}^{2}$ carbons at $\delta_{\mathrm{C}} 127.4(\mathrm{C}-1), 157.8(\mathrm{C}-4), 145.8\left(\mathrm{C}-3^{\prime}\right)$, and one carbonyl carbon at $\delta_{\mathrm{C}} 173.4(\mathrm{C}-8)$. The above-mentioned spectroscopic features as well as the COSY correlation between $\mathrm{H}-2 / 6$ and $\mathrm{H}-3 / 5$ (Figure $4 \mathrm{~A}$ ) were interpreted as characteristic for a para-substituted aromatic ring. Besides, $\mathrm{H}_{2}-\mathrm{1}^{\prime}$ and $\mathrm{H}-2^{\prime}$ were coupled as evidenced by the COSY correlation (Figure $4 \mathrm{~A}$ ). The key HMBC correlations from $\mathrm{H}_{3}-5^{\prime}$ to $\mathrm{C}-2^{\prime}, \mathrm{C}-3^{\prime}$, and $\mathrm{C}-4^{\prime}$, from $\mathrm{H}_{2}-1^{\prime}$ to $\mathrm{C}-3^{\prime}$, and from $\mathrm{H}-2^{\prime}$ to $\mathrm{C}-4^{\prime}$ and C-5' delineated an unsaturated and hydroxylated isoprene unit, (2-hydroxy-3-methylbut-3-en-1-yl)oxy (Figure 4A). Additional HMBC correlation from $\mathrm{H}_{2}-1^{\prime}$ to $\mathrm{C}-4$ showed that the isoprene unit was connected to the para-substituted aromatic ring via an oxygen atom. Furthermore, the interactive HMBC correlations from $\mathrm{H}_{2}-7$ to $\mathrm{C}-2, \mathrm{C}-6$, and C-8 constructed the other group (C7-C8) linked to the aromatic ring. The planar structure of 2 was therefore determined. A literature search revealed that it possessed the same planar structure as stachyline B, a secondary metabolite previously isolated from the sponge-derived fungus Stachylidium sp. [14]. The configuration at C-2' of stachyline B was determined as $S$ by Mosher's method [14]. Since 2 possessed the opposite sign of the optical rotation when compared to that of stachyline B (+16.1 in 2 vs -12 in stachyline B), the $R$ configuration was proposed for $\mathrm{C}-2^{\prime}$ of $\mathbf{2}$. X-ray diffraction crystallographic analysis enabled us to undoubtedly confirm its absolute configuration (Figure 4B). 
A

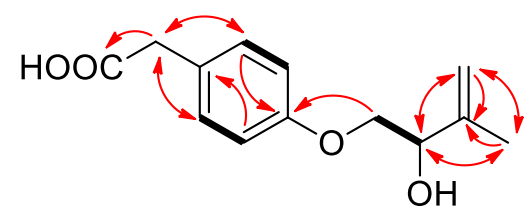

B

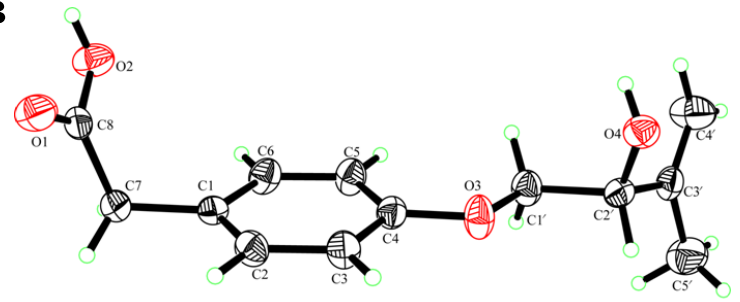

Figure 4. (A) COSY and key HMBC correlations of 2; (B) ORTEP (Oak Ridge Thermal-Ellipsoid Plot Program) diagram for the single-crystal X-ray structure of 2.

Compound 3 was obtained as a white amorphous powder and possessed a molecular formula of $\mathrm{C}_{14} \mathrm{H}_{18} \mathrm{O}_{4}$ by (+)-HRESIMS data $m / z 268.1548\left[\mathrm{M}+\mathrm{NH}_{4}\right]^{+}$and $273.1095[\mathrm{M}+\mathrm{Na}]^{+}$. With compound 2 in hand, the structure elucidation of 3 was quite straightforward. The ${ }^{1} \mathrm{H}$ and ${ }^{13} \mathrm{C} \mathrm{NMR}$ spectra of 3 (Table 1 ) closely resembled those of 2 , except that 3 had one methyl group $\left(\delta_{\mathrm{H} / \mathrm{C}} 3.58 / 51.6,8-\mathrm{OMe}\right)$ more than 2. Accordingly, $\mathbf{3}$ was elucidated as a methyl ester of $\mathbf{2}$. Because $\mathbf{3}$ is dextrorotatory, it was concluded that 3 also has $R$-configuration at C-2'.

In addition, another five previously reported metabolites including bisabolane-type sesquiterpenoids 4-6 and meroterpenoids 7 and 8 were also isolated in this study. They were identified as (7S,11S)-(+)-12-acetoxysydonic acid (4) [15], (S)-(+)-11-dehydrosydonic acid (5) [15], sydonic acid (6) [16], asperdemin (7) [17], and asperversin G (8) [18], respectively, by comparing their NMR data with those from the literature.

\subsection{Cytotoxicity of Compounds $\mathbf{1}-\mathbf{8}$}

The isolated compounds 1-8 were submitted to Cell Counting Kit-8 (CCK-8) colorimetric assays toward six human carcinoma cell lines (human lung adenocarcinoma epithelial cell line A549, human breast cancer cell line BT-549, human cervix carcinoma cell line HeLa, human liver carcinoma cell line HepG2, human breast adenocarcinoma cell line MCF-7, and human monocytic cell line THP-1) to estimate their cytotoxicities. Compound 3 exhibited cytotoxicity to the HepG2 cell line with an $\mathrm{IC}_{50}$ value of $22.0 \mu \mathrm{M}$. Furthermore, 5 also showed considerable activities against the A549 and THP-1 cell lines with $\mathrm{IC}_{50}$ values of 21.2 and $18.2 \mu \mathrm{M}$, respectively (Table 2). To determine whether the compounds could induce apoptosis, 4',6-diamidino-2-phenylindole (DAPI) staining was conducted using a confocal laser scanning microscope. We found that many cells had typical apoptotic features, such as fragmented/condensed nucleus and apoptotic body formation (Figure 5). All staining results indicated that 3 and 5 had apoptosis-inducing activity against the HepG2, A549, and THP-1 cell lines, respectively.

Table 2. Cytotoxicity of $\mathbf{1}-\mathbf{8}\left(\mathrm{IC}_{50}, \mu \mathrm{M}\right.$, mean $\left.\pm \mathrm{SD}, \mathrm{n}=3\right)$.

\begin{tabular}{ccccccc}
\hline Compound & A549 & BT-549 & HeLa & HepG2 & MCF-7 & THP-1 \\
\hline $\mathbf{1}$ & $>100$ & $>100$ & $>100$ & $>100$ & $>100$ & $>100$ \\
$\mathbf{2}$ & $>100$ & $87.3 \pm 3.5$ & $96.6 \pm 1.5$ & $>100$ & $>100$ & $>100$ \\
$\mathbf{3}$ & $70.0 \pm 1.2$ & $>100$ & $>100$ & $22.0 \pm 1.2$ & $>100$ & $>100$ \\
$\mathbf{4}$ & $63.6 \pm 2.6$ & $>100$ & $78.7 \pm 2.9$ & $>100$ & $>100$ & $78.7 \pm 1.9$ \\
$\mathbf{5}$ & $21.2 \pm 2.3$ & $>100$ & $61.7 \pm 2.2$ & $>100$ & $>100$ & $18.2 \pm 1.2$ \\
$\mathbf{6}$ & $>100$ & $>100$ & $>100$ & $>100$ & $>100$ & $>100$ \\
$\mathbf{7}$ & $>100$ & $>100$ & $>100$ & $>100$ & $>100$ & $>100$ \\
$\mathbf{8}$ & $>100$ & $>100$ & $>100$ & $>100$ & $>100$ & $>100$ \\
Epirubicin $^{\text {a }}$ & $6.6 \pm 0.5$ & $4.4 \pm 0.2$ & $2.2 \pm 0.3$ & $3.7 \pm 0.2$ & $3.9 \pm 0.1$ & $4.8 \pm 0.2$ \\
\hline
\end{tabular}



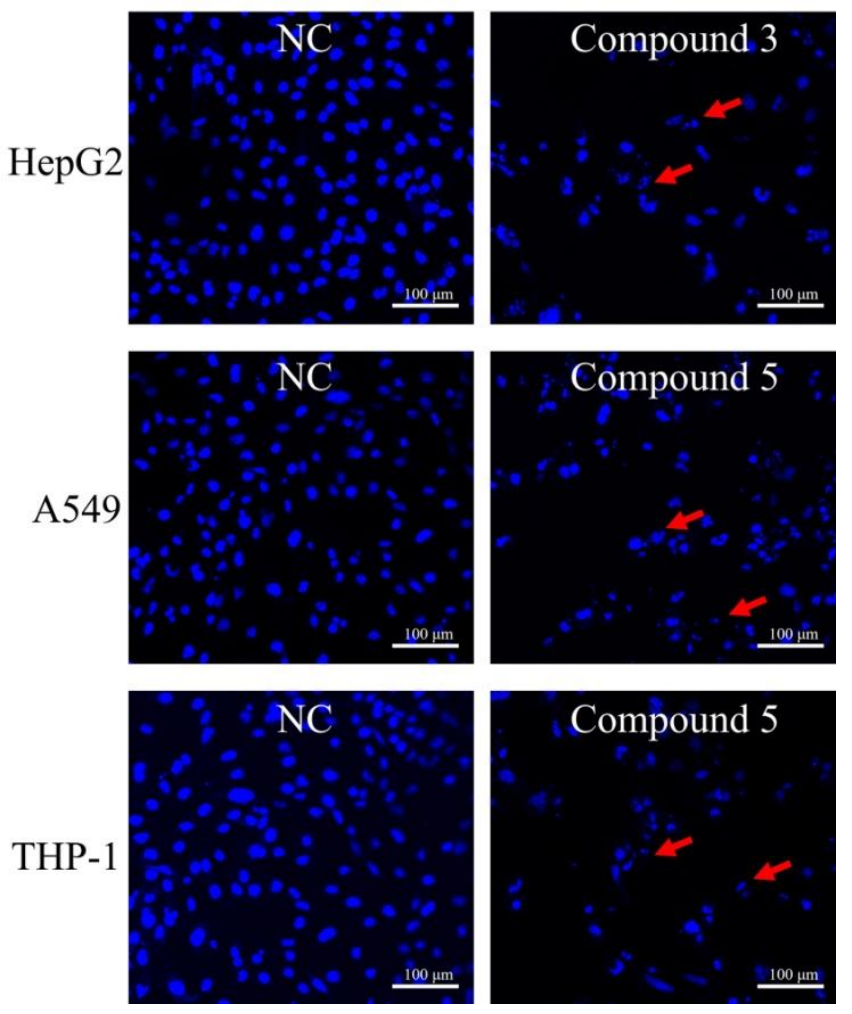

Figure 5. Apoptosis-related morphological changes were detected by staining cells with 4',6-diamidino-2-phenylindole (DAPI). Apoptotic cells were defined as those with blue-stained cells that exhibited a fragmented/condensed nucleus and apoptotic body (red arrow).

\section{Materials and Methods}

\subsection{General Experimental Procedures}

The UV spectra were measured using a Shimadzu UV-2700 spectrometer (Shimadzu Co., Ltd., Kyoto, Japan). The optical rotations were measured using a Jasco P-1020 automatic polarimeter (JASCO, Tokyo, Japan). The NMR spectra were recorded on an Agilent DD2 $500 \mathrm{MHz}$ NMR spectrometer (Agilent Technologies, Waldbronn, Germany) with tetramethylsilane (TMS) as an internal standard. The HRESIMS data were obtained in the positive ion mode on a Waters Xevo G2-XS QTof mass spectrometer (Waters, Milford, MA, USA). Commercially available silica gel (100-200 and 200-300 mesh, Qingdao Marine Chemical Inc., Qingdao, China), Lobar LiChroprep RP-18 (40-60 $\mu \mathrm{m}$, Merck, Darmstadt, Germany), and Sephadex LH-20 (Merck) were used for open column chromatography.

\subsection{Fungal Material}

The fungal strain LD-201810 was previously isolated from the marine red alga Grateloupia turuturu collected in August 2016 from Qingdao, China. This strain was identified as P. chrysogenum according to its morphological characteristics and sequencing of the ITS region (GenBank no. MT075873). The strain was deposited in the Key Laboratory of Marine Biotechnology at the Universities of Shandong (Ludong University), School of Life Sciences, Ludong University, Yantai, China.

\subsection{Fermentation, Extraction, and Isolation}

The fermentation was performed statically on sterilized solid rice medium (70 $\mathrm{g}$ of rice, $0.1 \mathrm{~g}$ of corn flour, $0.3 \mathrm{~g}$ of peptone, $0.1 \mathrm{~g}$ of monosodium glutamate, and $100 \mathrm{~mL}$ of filtered seawater in each $1 \mathrm{~L}$ Erlenmeyer flask) at room temperature. After incubation for 30 days, a total of 50 flasks of cultured mycelium were exhaustively extracted with EtOAc $(3 \times 10 \mathrm{~L})$. Then, the organic phase was filtered 
and evaporated under reduced pressure to afford $40.6 \mathrm{~g}$ of EtOAc crude extract. Chromatographic fractionation of the EtOAc crude extract was performed using an open silica gel vacuum liquid chromatography (VLC) gradient system (bed $10 \times 60 \mathrm{~cm}$, silica gel $300 \mathrm{~g}, 100-200 \mathrm{mesh}$ ); the column was eluted with mixtures of petroleum ether (PE)-EtOAc (from 5:1 to 1:1, v/v, collected $1 \mathrm{~L}$ for each fraction) and dichloromethane (DCM)-methanol (MeOH) (from 20:1 to 5:1, v/v, collected $1 \mathrm{~L}$ for each fraction). A total of eight fractions, i.e., fractions A (11.2 g), B (2.6 g), C (5.8 g), D (5.2 g), E (2.6 g), F $(6.0 \mathrm{~g}), \mathrm{G}(2.1 \mathrm{~g})$, and $\mathrm{H}(1.9 \mathrm{~g})$, were obtained and concentrated under reduced pressure. Fraction A (11.2 g), eluted with PE-EtOAc (5:1, v/v, collected $2 \mathrm{~L}$ eluent), was re-fractionated by a silica gel column (bed $8 \times 80 \mathrm{~cm}$, silica gel $200 \mathrm{~g}$, 200-300 mesh; PE-EtOAc gradient, from 10:1 to 1:1, v/v) to yield subfractions A1 and A2. Fraction A1 (4.5 g, eluted with PE-EtOAc 5:1, v/v, collected $1 \mathrm{~L}$ eluent) was subjected to a Sephadex LH-20 column $(\mathrm{MeOH}$, bed $1.5 \times 135 \mathrm{~cm})$ to obtain $7(23.6 \mathrm{mg})$. Fraction A2 (3.2 g, eluted with PE-EtOAc 1:1, v/v, collected $1 \mathrm{~L}$ eluent) was purified using preparative thin layer chromatography (PTLC, plate: $20 \times 20 \mathrm{~cm}$; developing solvents: $\mathrm{DCM}-\mathrm{MeOH}, 20: 1, v / v, 160 \mathrm{~mL}$ ) to obtain 8 (42.3 mg). Fraction C (5.8 g), eluted with PE-EtOAc (1:1, v/v, collected 1 L eluent), was further re-fractionated by a silica gel column (bed $8 \times 80 \mathrm{~cm}$, silica gel $200 \mathrm{~g}, 200-300$ mesh; DCM-MeOH, from 20:1 to $10: 1, v / v)$ to yield subfractions C1 and C2. Fraction C1 (1.2 g, eluted with DCM-MeOH 20:1, $v / v$, collected $500 \mathrm{~mL}$ eluent) was purified by a Sephadex LH-20 column $(\mathrm{MeOH}$, bed $1.5 \times 135 \mathrm{~cm})$ to obtain $1(10.5 \mathrm{mg})$. Fraction E (2.6 g) was subjected to reversed-phase column chromatography (bed $2 \times 5 \mathrm{~cm}$ ) over Lobar LiChroprep RP-18 with a MeOH- $\mathrm{H}_{2} \mathrm{O}$ gradient system (from 1:9 to 10:0, $v / v$, collected $1.2 \mathrm{~L}$ for each fraction) to afford five subfractions (Fr.E1-E5). Fr.E1 (123 mg, eluted with $\mathrm{MeOH}-\mathrm{H}_{2} \mathrm{O} 3: 7, v / v$ ) was purified using prep-HPLC (SunFire ${ }^{\circledR} \mathrm{C} 18,250 \mathrm{~mm} \times 10 \mathrm{~mm}, 5 \mu \mathrm{m}$; mobile phase: $50 \% \mathrm{MeOH}-\mathrm{H}_{2} \mathrm{O}$; flow rate: $2 \mathrm{~mL} / \mathrm{min}$; UV detection: $\left.235 \mathrm{~nm}\right)$ to afford $2\left(8.5 \mathrm{mg}, t_{\mathrm{R}}\right.$ $12.6 \mathrm{~min})$. Fr.E2 (89 mg, eluted with $\left.\mathrm{MeOH}-\mathrm{H}_{2} \mathrm{O} 2: 3, v / v\right)$ was subjected to PTLC (plate: $20 \times 20 \mathrm{~cm}$; developing solvents: DCM-acetone-acetic acid, 10:1:0.05, v/v, $80 \mathrm{~mL})$ to afford $6(9.5 \mathrm{mg})$. Fr.E3 $\left(120 \mathrm{mg}\right.$, eluted with $\left.\mathrm{MeOH}-\mathrm{H}_{2} \mathrm{O} 1: 1, v / v\right)$ was chromatographed on a prep-HPLC column (SunFire ${ }^{\circledR}$ $\mathrm{C} 18,250 \mathrm{~mm} \times 10 \mathrm{~mm}, 5 \mu \mathrm{m}$; mobile phase: $60 \% \mathrm{MeOH}-\mathrm{H}_{2} \mathrm{O}$; flow rate: $2 \mathrm{~mL} / \mathrm{min}$; UV detection: $235 \mathrm{~nm}$ ) to obtain $3\left(12.3 \mathrm{mg}, t_{\mathrm{R}} 15.0 \mathrm{~min}\right)$. Fr.E4 (200 mg, eluted with $\left.\mathrm{MeOH}-\mathrm{H}_{2} \mathrm{O} 3: 2, v / v\right)$ was subjected to PTLC (plate: $20 \times 20 \mathrm{~cm}$; developing solvents: $\mathrm{DCM}-\mathrm{MeOH}-\mathrm{CH}_{3} \mathrm{CO}_{2} \mathrm{H}, 10: 1: 0.05, v / v$, $4 \times 40 \mathrm{~mL})$ to afford $4(11.3 \mathrm{mg})$ and $5(26.3 \mathrm{mg})$.

Penilactonol A (1): colorless oil; $[\alpha]^{25} \mathrm{D}+7.3^{\circ}\left(c\right.$ 0.20, MeOH); UV (MeOH) $\lambda_{\max }(\log \varepsilon) 207(0.22) \mathrm{nm}$; $\operatorname{ECD}(0.20 \mathrm{mg} / \mathrm{mL}, \mathrm{MeOH}) \lambda_{\max }(\Delta \varepsilon) 224(+1.80) \mathrm{nm} ;{ }^{1} \mathrm{H}$ and ${ }^{13} \mathrm{C}$ NMR data, Table $1 ;(+)$-HRESIMS $\mathrm{m} / \mathrm{z}$ 185.0803 [M+ H] $]^{+}$(calcd for $\left.\mathrm{C}_{9} \mathrm{H}_{13} \mathrm{O}_{4}, 185.0808\right)$.

(2'R)-Stachyline B (2): colorless needles; $\mathrm{mp} 188-190^{\circ} \mathrm{C} ;[\alpha]^{25} \mathrm{D}+16.1^{\circ}$ (c $\left.0.25, \mathrm{MeOH}\right) ; \mathrm{UV}(\mathrm{MeOH}) \lambda_{\max }$ $(\log \varepsilon) 203$ (3.37), 228 (3.81), 278 (3.12), $285(2.79) \mathrm{nm} ;{ }^{1} \mathrm{H}$ and ${ }^{13} \mathrm{C}$ NMR data, Table 1; (+)-HRESIMS m/z $254.1389\left[\mathrm{M}+\mathrm{NH}_{4}\right]^{+}$(calcd for $\left.\mathrm{C}_{13} \mathrm{H}_{20} \mathrm{NO}_{4}, 254.1387\right)$ and $259.0942[\mathrm{M}+\mathrm{Na}]^{+}$(calcd for $\mathrm{C}_{13} \mathrm{H}_{16} \mathrm{O}_{4} \mathrm{Na}$, 259.0941).

(2'R)-Westerdijkin A (3): white amorphous powder; $[\alpha]^{25} \mathrm{D}+70.3^{\circ}$ (c $\left.0.30, \mathrm{MeOH}\right) ; \mathrm{UV}(\mathrm{MeOH}) \lambda_{\max }$ (log $\varepsilon) 201$ (3.33), 226 (3.79), 277 (3.06), $283(2.80) \mathrm{nm} ;{ }^{1} \mathrm{H}$ and ${ }^{13} \mathrm{C}$ NMR data, Table 1; (+)-HRESIMS $\mathrm{m} / \mathrm{z}$ $268.1548\left[\mathrm{M}+\mathrm{NH}_{4}\right]^{+}$(calcd for $\left.\mathrm{C}_{14} \mathrm{H}_{22} \mathrm{NO}_{4}, 268.1543\right)$ and $273.1095[\mathrm{M}+\mathrm{Na}]^{+}$(calcd for $\mathrm{C}_{14} \mathrm{H}_{18} \mathrm{O}_{4} \mathrm{Na}$, 273.1097).

\subsection{Measurement of ICD Spectrum of $\mathbf{1}$ Using $\mathrm{Mo}_{2}(\mathrm{OAc})_{4}$}

The ICD spectrum was measured using spectroscopy-grade anhydrous $\mathrm{MeOH}$. A mixture of the ligand (1) and $\mathrm{Mo}_{2}(\mathrm{OAc})_{4}$ in $\mathrm{MeOH}$ in an approximate 1:2 molar ratio was subjected to ICD measurement. The first $\mathrm{CD}$ spectrum was recorded immediately after mixing, and its time evolution was monitored until stationary ICD was reached about $10 \mathrm{~min}$ after mixing. After the inherent $\mathrm{CD}$ data of the compound were subtracted, the ICD spectrum was normalized to a molar concentration of 1 and was presented as the $\Delta \varepsilon^{\prime}$ values. The observed signs of the Cotton effect near $400 \mathrm{~nm}$ in the ICD were correlated to the absolute configuration of the 1,2-diol moiety [11]. 


\subsection{Computational Section}

The conformational search was conducted via the conformer-rotamer ensemble sampling tool (CREST) $[19,20]$. Density-functional theory (DFT) calculations were carried out using the Gaussian 16 program [21]. The conformers within an energy window of $4 \mathrm{kcal} / \mathrm{mol}$ were optimized with DFT calculations at the B3LYP/6-31G(d) level of theory with Grimme's D3 dispersion correction. Next, energies of all optimized conformations were evaluated by M06-2X/6-311+g $(2 d, p)$ with D3 dispersion correction. Those conformers accounting for over $98 \%$ of the population were subjected to TDDFT ECD calculations at the CAM-B3LYP/def2-SVP level of theory in MeOH with the IEFPCM solvent model, respectively. For each conformer, 30 excited states were calculated [22]. The calculated ECD curves were generated using Multiwfn 3.6 software with a full width at half maximum (FWHM) for each peak set to $0.4 \mathrm{eV}$ [23].

\subsection{X-ray Crystallographic Analysis of $\mathbf{2}$}

Single-crystal X-ray diffraction data of 2 were obtained on an Agilent Xcalibur Eos Gemini Charge Couple Device (CCD) plate diffractometer using graphite monochromatized $\mathrm{Cu} / \mathrm{K} \alpha$ radiation $(\lambda=1.54178 \AA$ ). The structures were solved by direct methods with the SHELXTL software package [24]. All non-hydrogen atoms were refined anisotropically. The $\mathrm{H}$ atoms were located using geometrical calculations, and their positions and thermal parameters were fixed during the structure refinement. The structure was refined using full-matrix least-squares techniques [25]. Crystallographic data of 2 have been deposited in the Cambridge Crystallographic Data Centre (CCDC) with the CCDC number of 1999572. The data can be obtained free of charge via CCDC, 12 Union Road, Cambridge CB21EZ, UK (e-mail: deposit@ccdc.cam.ac.uk).

Crystal data for compound 2: $\mathrm{C}_{13} \mathrm{H}_{16} \mathrm{O}_{4}, \mathrm{~F} . \mathrm{W} .=236.26$, monoclinic space group P2(1), unit cell dimensions $a=5.8770(7) \AA, b=7.7029(13) \AA, c=27.763(4) \AA, V=1256.8(3) \AA^{3}, \alpha=\beta=\gamma=90^{\circ}, Z=4$, $d_{\text {calcd }}=1.249 \mathrm{mg} / \mathrm{m}^{3}$, crystal dimensions $0.36 \times 0.22 \times 0.12 \mathrm{~mm}, \mu=0.762 \mathrm{~mm}^{-1}, F(000)=504$. The 1774 measurements yielded 1500 independent reflections after equivalent data were averaged, and Lorentz and polarization corrections were applied. The final refinement gave $R_{1}=0.0379$ and $w R_{2}=0.1050$ $[I>2 \sigma(I)]$. The Flack parameter was $-0.2(3)$ in the final refinement for all 1774 reflections with 157 Friedel pairs.

\subsection{Cytotoxic Assays}

The CCK-8 colorimetric method and DAPI staining were used to determine the cytotoxicities of compounds 1-8 against six human carcinoma cell lines (A549, BT-549, HeLa, HepG2, MCF-7, and THP-1) [26]. For the DAPI staining, HepG2, A549, and THP-1 cells were initially incubated for $24 \mathrm{~h}$ and then exposed to compounds for $48 \mathrm{~h}$. Then, the cells were fixed with $70 \%$ ethanol. Subsequently, the cells were stained with $4 \mathrm{ng} / \mathrm{mL}$ DAPI at $4{ }^{\circ} \mathrm{C}$ for $5-10 \mathrm{~min}$. Stained cells in each group were observed using a confocal laser scanning microscope.

\subsection{Statistical Analysis}

In this study, experiments were performed in triplicate and in parallel. For data analysis, the SPSS 21.0 software package (Chicago, IL, USA) was used to detect the half-maximal inhibitory concentration $\left(\mathrm{IC}_{50}\right)$ value.

\section{Conclusions}

Secondary metabolites produced by marine-derived fungi have gained remarkable attention due to their intriguing structures and potential pharmacological applications. In this study, a new pentaketide derivative, penilactonol A (1), and two previously unreported hydroxyphenylacetic acid derivatives, $\left(2^{\prime} R\right)$-stachyline B (2) and $\left(2^{\prime} R\right)$-westerdijkin A (3), together with five known metabolites including bisabolane-type sesquiterpenoids $4-6$ and meroterpenoids 7 and 8 , were isolated from the 
solid culture of marine alga-associated fungus P. chrysogenum LD-201810. It should be pointed out that $\mathbf{2}$ and $\mathbf{3}$ adapt the $2^{\prime} R$-configuration as compared to known hydroxyphenylacetic acid-derived and $O$-prenylated natural products. The cytotoxicities of the isolated compounds were evaluated. Compound 3 exhibited cytotoxicity to the HepG2 cell line with an $\mathrm{IC}_{50}$ value of $22.0 \mu \mathrm{M}$, whereas 5 showed considerable activities against A549 and THP-1 cell lines with $\mathrm{IC}_{50}$ values of 21.2 and $18.2 \mu \mathrm{M}$, respectively. Moreover, DAPI staining indicated that 3 and 5 had apoptosis-inducing activity. The present study may provide further proof that marine natural products are promising candidates for the discovery of new lead compounds of antitumor drugs.

Supplementary Materials: The following are available online at http://www.mdpi.com/1660-3397/18/5/276/s1. Figures S1-S19: ${ }^{1} \mathrm{H}$ NMR, ${ }^{13} \mathrm{C}$ NMR, HSQC, ${ }^{1} \mathrm{H}-{ }^{1} \mathrm{H}$ COSY, HMBC, NOESY, and HRESIMS spectra of compounds 1-3; Figures S20-S28: Cytotoxicity of 1-8 and epirubicin; Tables S1-S19: Gibbs free energies and equilibrium populations of the calculated conformers.

Author Contributions: Conceptualization, J.-X.T. and Y.-H.B.; writing-original draft preparation, L.-L.J.; writing—review and editing, Y.-Z.L., T.F., H.-W.Z., and X.Y.; funding acquisition, X.-X.Z., W.W., and J.-L.Z. All authors have read and approved the final manuscript.

Funding: This research was supported by the National Key Research and Development Program of China (Grant No. 2016YFD0501010, 2017YFD0500806 and 2018YFD0501402), the Major Agricultural Applied Technological Innovation Projects of Shandong Province (to X.X.Z.), the Key Research and Development Plan of Yantai (No. 2018XSCC045), the Foundation of Third Institute of Oceanography SOA (2018021 and 2017001), and the Natural Science Foundation of Fujian Province (2018J01064).

Conflicts of Interest: The authors declare no conflict of interest.

\section{References}

1. Hou, X.-M.; Xu, R.-F.; Gu, Y.-C.; Wang, C.; Shao, C.-L. Biological and Chemical Diversity of Coral-Derived Microorganisms. Curr. Med. Chem. 2015, 22, 3707-3762. [CrossRef] [PubMed]

2. Carroll, A.R.; Copp, B.R.; Davis, R.A.; Keyzers, R.A.; Prinsep, M.R. Marine natural products. Nat. Prod. Rep. 2019, 36, 122-173. [CrossRef] [PubMed]

3. Shah, M.; Sun, C.; Sun, Z.; Zhang, G.; Che, Q.; Gu, Q.; Zhu, T.; Li, D. Sun Antibacterial Polyketides from Antarctica Sponge-Derived Fungus Penicillium sp. HDN151272. Mar. Drugs 2020, 18, 71. [CrossRef] [PubMed]

4. Xu, K.; Yuan, X.-L.; Li, C.; Li, X.-D. Recent Discovery of Heterocyclic Alkaloids from Marine-Derived Aspergillus Species. Mar. Drugs 2020, 18, 54. [CrossRef]

5. Rateb, M.E.M.; Ebel, R. Secondary metabolites of fungi from marine habitats. Nat. Prod. Rep. 2011, 28, 290. [CrossRef]

6. Ji, N.-Y.; Wang, B.-G. Mycochemistry of marine algicolous fungi. Fungal Divers. 2016, 80, 301-342. [CrossRef]

7. Zhang, P.; Li, X.; Wang, B.-G. Secondary Metabolites from the Marine Algal-Derived Endophytic Fungi: Chemical Diversity and Biological Activity. Planta Medica 2016, 82, 832-842. [CrossRef]

8. Soldatou, S.; Baker, B.J. Cold-water marine natural products, 2006 to 2016. Nat. Prod. Rep. 2017, 34, 585-626. [CrossRef]

9. Chen, X.-W.; Li, C.-W.; Cui, C.-B.; Hua, W.; Zhu, T.-J.; Gu, Q.-Q. Nine New and Five Known Polyketides Derived from a Deep Sea-Sourced Aspergillus sp. 16-02-1. Mar. Drugs 2014, 12, 3116-3137. [CrossRef]

10. Huang, L.; Ding, L.; Li, X.; Wang, N.; Yan, Y.; Yang, M.; Cui, W.; Naman, C.B.; Cheng, K.; Zhang, W.; et al. A new lateral root growth inhibitor from the sponge-derived fungus Aspergillus sp. LS45. Bioorg. Med. Chem. Lett. 2019, 29, 1593-1596. [CrossRef]

11. Di Bari, L.; Pescitelli, G.; Pratelli, C.; Pini, D.; Salvadori, P. Determination of absolute configuration of acyclic 1,2-diols with Mo2(OAc)4. 1. Snatzke's method revisited. J. Org. Chem. 2001, 66, 4819-4825. [CrossRef] [PubMed]

12. Frelek, J.; Ruskowska, P.; Suszczynska, A.; Szewczyk, K.; Osuch, A.; Jarosz, S.; Jagodzinski, J. Configurational assignment of sugar erythro-1,2-diols from their electronic circular dichroism spectra with dimolybdenum tetraacetate. Tetrahedron: Asymmetry 2008, 19, 1709-1713. [CrossRef] 
13. Xia, M.-W.; Cheng-Bin, C.; Li, C.-W.; Wu, C.-J. Three New and Eleven Known Unusual C25 Steroids: Activated Production of Silent Metabolites in a Marine-Derived Fungus by Chemical Mutagenesis Strategy using Diethyl Sulphate. Mar. Drugs 2014, 12, 1545-1568. [CrossRef] [PubMed]

14. Almeida, C.; Part, N.; Bouhired, S.; Kehraus, S.; König, G.M. Stachylines A-D from the Sponge-Derived Fungus Stachylidium sp. J. Nat. Prod. 2011, 74, 21-25. [CrossRef]

15. Lu, Z.; Zhu, H.; Fu, P.; Wang, Y.; Zhang, Z.; Lin, H.; Liu, P.; Zhuang, Y.; Hong, K.; Zhu, W. Cytotoxic Polyphenols from the Marine-Derived Fungus Penicillium expansum. J. Nat. Prod. 2010, 73, 911-914. [CrossRef]

16. Hamasaki, T.; Nagayama, K.; Hatsuda, Y. Two new metabolites, sydonic acid and hydroxysydonic acid from Aspergillus sydowi. Agric. Biol. Chem. 1978, 42,37-40. [CrossRef]

17. Yurchenko, A.N.; Smetanina, O.F.; Kalinovsky, A.I.; Pivkin, M.V.; Dmitrenok, P.S.; Kuznetsova, T.A. A new meroterpenoid from the marine fungus Aspergillus versicolor (Vuill.) Tirab. Russ. Chem. Bull. 2010, 59, 852-856. [CrossRef]

18. Li, H.; Sun, W.; Deng, M.; Qi, C.; Chen, C.; Zhu, H.; Luo, Z.; Wang, J.; Xue, Y.; Zhang, Y. Asperversins A and $\mathrm{B}$, two novel meroterpenoids with an unusual 5/6/6/6 ring from the marine-derived fungus Aspergillus versicolor. Mar. Drugs 2018, 16, 177. [CrossRef]

19. Pracht, P.; Bohle, F.; Grimme, S. Automated exploration of the low-energy chemical space with fast quantum chemical methods. Phys. Chem. Chem. Phys. 2020, 22, 7169-7192. [CrossRef]

20. Grimme, S. Exploration of Chemical Compound, Conformer, and Reaction Space with Meta-Dynamics Simulations Based on Tight-Binding Quantum Chemical Calculations. J. Chem. Theory Comput. 2019, 15, 2847-2862. [CrossRef]

21. Frisch, M.J.; Trucks, G.W.; Schlegel, H.B.; Scuseria, G.E.; Robb, M.A.; Cheeseman, J.R.; Scalmani, G.; Barone, V.; Petersson, G.A.; Nakatsuji, H.; et al. Gaussian 16 Rev. C.01; Gaussian, Inc.: Wallingford, CT, USA, 2016.

22. Pescitelli, G.; Bruhn, T. Good Computational Practice in the Assignment of Absolute Configurations by TDDFT Calculations of ECD Spectra. Chirality 2016, 28, 466-474. [CrossRef] [PubMed]

23. Lu, T.; Chen, F. Multiwfn: A multifunctional wavefunction analyzer. J. Comput. Chem. 2011, 33, 580-592. [CrossRef] [PubMed]

24. Sheldrick, G.M. SHELXTL, Structure Determination Software Programs; Bruker Analytical X-ray System Inc.: Madison, WI, USA, 1997.

25. Sheldrick, G.M. SHELXL-97 and SHELXS-97, Program for X-ray Crystal Structure Solution and Refinement; University of Göttingen: Göttingen, Germany, 1997.

26. Yuan, X.-L.; Zhang, P.; Liu, X.-M.; Du, Y.-M.; Hou, X.-D.; Cheng, S.; Zhang, Z.-F. Cytological Assessments and Transcriptome Profiling Demonstrate that Evodiamine Inhibits Growth and Induces Apoptosis in a Renal Carcinoma Cell Line. Sci. Rep. 2017, 7, 12572. [CrossRef] [PubMed] 